REVIEW

\title{
Hormone-related tumors in transsexuals receiving treatment with cross-sex hormones
}

\author{
Andreas Mueller and Louis Gooren ${ }^{1}$ \\ Department of Obstetrics and Gynecology, Erlangen University Hospital, Universitaetsstr. 21-23, D-91054 Erlangen, Germany and ${ }^{1}$ Department of \\ Endocrinology, VU University Medical Center, de Boelelaan 1117, 1081 HV Amsterdam, The Netherlands \\ (Correspondence should be addressed to L Gooren; Email: louisjgooren@gmail.com)
}

\begin{abstract}
Objective: To assess the risk of development of hormone-related tumors in transsexuals receiving treatment with cross-sex hormones.

Design: Description of cases of transsexuals who have developed a hormone-related malignancy observed in their own clinic or reported in the literature. Recommendations for early diagnosis and prevention are presented.

Methods: Review of the literature in PubMed.

Results: In male-to-female transsexuals receiving estrogen administration, lactotroph adenomas, breast cancer, and prostate cancer have been reported. In female-to-male transsexuals receiving treatment with testosterone, a single case of breast carcinoma and several cases of ovarian cancer have been reported. So far endometrial cancer has not been encountered though it remains a potential malignant development.

Conclusions: There are so far only a few cases of hormone-related cancer in transsexuals. There may be an underreporting. The probability of a hormone-related tumor increases with the duration of exposure to cross-sex hormones and the aging of the population of transsexuals.
\end{abstract}

European Journal of Endocrinology 159 197-202

\section{Introduction}

For transsexuals, the acquisition of the secondary sex characteristics of the other gender is fundamental to sex reassignment. The acquisition of these secondary sex characteristics is contingent on sex steroids. There are presently no indications that there are fundamental sex differences in sensitivity to hormone action of sex steroids. Nearly all hormone-related biochemical processes can be sex-reversed by the administration of cross-sex hormones.

The typical transsexual requesting treatment is young to middle-aged and healthy and, therefore, there are usually no or few absolute or relative contraindications against cross-sex hormone administration.

After reassignment surgery, which includes gonadectomy, hormone therapy must be continued. It is reasonable to assume that the principles of treatment are similar to those of other subjects without own gonadal hormonal secretion. An unresolved question is whether in the long term the administration of cross-sex hormones is safe, at least as safe as administration of sex steroids to a subject receiving long-term sex-appropriate sex steroids. While the initial treatment with cross-sex hormones is mainly concentrated in specialized centers, complications occurring in the longer term are often seen in general practice, and these complications are only occasionally reported in the scientific literature. So, it is likely that there is an underreporting of (serious) complications of cross-sex hormone therapy. The authors have been contacted by other physicians with regard to medical occurrences in transsexuals, but these cases are often lost in follow-up and registration/reporting of (potential) complications of cross-sex hormonal treatment does not materialize. The latter situation prevents a fair comparison with epidemiological data in the general population. Recently, a website has been opened for reporting side effects of cross-sex hormone treatment (http://www.wpath.org/ resources_transgender.cfm).

This contribution focuses on the risk of development of hormone-dependent malignancies in transsexuals. It will try to formulate some recommendations to reduce the risk of development of hormone-related malignancies and strategies which might lead to early diagnosis.

In this regard, there are a number of considerations. There are no evidence-based recommendations for optimal hormonal treatment regimens for transsexuals, but there are a number of expert opinions in the literature (1-4). As yet, there are no recommendations as to what age cross-sex hormone administration must be continued. Should, for instance, estrogen 
administration to male-to-female transsexuals (MTF) follow the guidelines formulated for postmenopausal women and should the administration of estrogens be discontinued at a certain age? MTF themselves are usually reluctant to stop administration of hormones for fear that the secondary sex characteristics of the acquired sex will diminish. And there is presently no evidence-based recommendation to make on risks/ benefits of continuing/stopping hormones. The duration of sex steroid administration is probably an element in the risk of development of hormone-related malignancies.

Health insurance policies vary with regard to their coverage of medical expenses related to sex-reassignment treatment. Broadly speaking, most transsexuals in Western Europe undergo sex-reassignment surgery within a time frame of 2-3 years after initiation of cross-sex hormones. In other parts of the world transsexuals, for financial or other reasons, are not operated within this time frame. Long-term exposure of their gonads/genitalia and breasts to cross-sex hormones may involve greater risk of development of malignancies.

While this should not be generalized to the entire population of transsexuals, part of the population, particularly those that receive their cross-sex hormones outside of official medicine, use abnormally high doses of cross-sex hormones with a potential impact on the development of malignancies.

\section{Cross-sex hormones and hormone- dependent tumors}

Some cancers of reproductive organs are hormone related. The biology of hormone-dependent tumors differs from tissue to tissue. The Women's Health Initiative Study has recently demonstrated that women receiving estrogen plus progestin hormone replacement therapy (HRT) have an increased risk of invasive breast carcinoma, but women receiving estrogen only (estrogen replacement therapy) exhibit no increased risk of breast carcinoma (5). By contrast, the risk of endometrial carcinoma increases with estrogen replacement therapy, while HRT reduces the risk of endometrial carcinoma. These clinical findings suggest that the biological roles of estrogen and progestin in tumor development are different between the endometrium and the breast, even though both are considered 'estrogen-dependent tissues' (6). This discrepancy might be explained by the different roles of enzymes involved in the formation of active sex steroids in these tissues. The concentration of these enzymes is dissimilar between endometrial and breast carcinoma resulting in different effects of estrogens and progestins in tumor development in these tissues (7).

So far not many hormone-dependent tumors have been reported in hormonally treated female-to-male transsexuals (FTM) and they seem a rare occurrence in MTF. The first documented hormone treatments of transsexuals started in the 1970s and the length of time of exposure to hormones may have been too short for tumors to manifest themselves. In addition, transsexualism is a rare phenomenon (the highest estimates are 1:12 000 males and 1:30 000 females) (8). Moreover, the prevalence of hormone-dependent tumors is low, and this may lead to an underestimation of tumors since most clinicians will only encounter single cases which are less likely to be reported in the literature than larger numbers. Therefore, the conclusion that hormonerelated tumors are not highly prevalent among the transsexual population must be drawn with great caution.

MTF, as a rule, use higher doses of estrogens than women lacking production of gonadal homones. Compared with hypogonadal women, exposure of transsexuals to estrogens used to be over a shorter period of lifetime, since transsexuals mostly start crosssex hormone treatment well after puberty, though this is changing. Presently, adolescent transsexuals may be eligible for cross-sex hormone treatment. Furthermore, transsexuals beyond the age of 50 or 60 years have a strong inclination to continue cross-sex hormones increasing their period of time of exposure to sex steroids. The following is a summary of reports in the literature on tumors in transsexuals, and some recommendations are given on caveats, possible prevention and early diagnosis.

\section{Lactotroph adenoma}

Several cases of lactotroph adenoma (prolactinoma) following high-dose estrogen administration have been reported in patients with normal serum prolactin concentrations before therapy (9-12). The Amsterdam gender clinic recently encountered a case of development of a pituitary microprolactinoma in an MTF, only occurring after 14 years of normal-dosed estrogen treatment. Though causality has not been established, we recommend that serum prolactin levels continue to be monitored in estrogen-treated MTF in the long term.

\section{Breast cancer}

There are two reports of MTF who developed breast carcinomas while receiving estrogen treatment $(13,14)$. Breast fibroadenomas in MTF receiving hormonal treatment have been observed. In the Amsterdam gender clinic, no single case of breast cancer has been observed in a series of approximately 2200 MTF, cumulative over 30 years, but recently one case has been diagnosed. On the basis of the above information, one would be inclined to think that breast carcinomas in MTF are rare. But it has to be kept in mind that follow-up of 2200 subjects, with a strong variation in estrogen exposure (from 1 to 25 years), do not allow firm conclusions as to assessing risks. Aging 
is a factor in the development of cancer, and prolonged exposure to estrogens may also prove to be a factor. Indeed, the risk of developing breast cancer is strongly associated with exposure to estrogens in women and hence the use of anti-estrogens as an endocrine treatment option in breast cancer. However, there is only a slight indication of increased estrogen receptor levels in nonneoplastic tissue in breast cancer cases (15). Moreover, the expression of these hormone receptors does not always imply a response to treatment with anti-estrogens and patients who experience response at first may become resistant after prolonged treatment (16). It might well be that tissue-specific hormone actions and local hormone concentrations are more relevant than hormonal levels in the peripheral circulation. Nowadays, local enzymes involved in the formation of active sex steroids in the tissue itself are believed to play a major role in cancer formation ( 7 ). The class of $17 \beta$-hydroxysteroid dehydrogenases are enzymes involved in the formation of active sex steroids locally in the tissues itself upon estrogen replacement therapy (6). Another enzyme is aromatase, also involved in local estrogen synthesis in the peripheral tissues. Recently, this enzyme has also been studied as a possible target enzyme of endocrine treatment regimes and the use of aromatase inhibitors was successful in large clinical studies and is now commonly used in women with breast cancer $(17,18)$. As stated above, estrogen-alone treatment exhibits no increased risk of breast carcinoma and is believed to be safer than combined estrogen plus progestin therapy (5).

The question as to the age at which estrogen treatment in MTF should be terminated has not been conclusively answered.

There is a higher risk of developing breast carcinoma in men who carry germline mutations in the BRCA2 gene than men in the general population (19). Mutations in the BRCA1 gene may also constitute a higher risk for breast carcinoma. These risk factors also apply to women, so, upon taking a medical history it is recommended to enquire about familial occurrence of breast carcinomas. In any case, in addition to regular medical examination, breast self-examination must be part of the monitoring of estrogen administration, following the same guidelines that exist for other women, with clinical examinations every year or twice a year and self-examinations every month. The guidelines for mammography differ from country to country, and therefore, a general recommendation is very difficult to make, but an examination every 12-24 months if the initial examination shows no abnormalities, seems reasonable.

Amazingly, breast cancer has been reported in an FTM after bilateral subcutaneous mastectomy while receiving treatment with testosterone. This occurred in postoperative residual mammary tissue after 10 years of treatment with testosterone, which is partially aromatized to estradiol (20). The issue of the role of androgens in female breast cancer has not been conclusively resolved. Some authors have described androgens as a risk factor (21), others view it as protective against cancer development (22-24). It is the position of the North American Menopause Society that there are no randomized controlled trials of sufficient size and duration to evaluate the effect of testosterone treatment on breast cancer risk in postmenopausal or menopausal women (25). Testosterone enanthate has been approved in both the United States and Canada for the treatment of metastatic breast cancer in the 1950s.

It is of note that androgens (both endogenous and administered) are partially aromatized to estradiol, so FTM receiving testosterone administration still have substantial levels of circulating estrogens (24). As a consequence, in FTM who have not undergone mastectomy, clinicians should be aware of the potential of development of a breast carcinoma.

\section{Benign prostate hyperplasia and prostate cancer}

The prostate is not removed with sex reassignment surgery. Prostatectomy is a surgically cumbersome operation, with possible complications, such as urinary incontinence. As expected, the prostate volume shrinks after androgen deprivation. Estrogen exposure does not induce signs of hyperplasia or (pre)malignancy (26). Two cases of benign prostate hyperplasia, requiring transurethral prostate resection, have been described in subjects who had been orchidectomized and had been treated with estrogens only for more than 20 years. Another case of squamous metaplasia of the verumontanum has been reported leading to obstruction due to hypertrophy (27).

Three cases of prostate cancer in MTF taking estrogen have been reported (28-30). It is not clear whether these cancers were estrogen sensitive, or whether they were present prior to beginning estrogen administration and then subsequently de-differentiated to become androgen independent. These patients were each over 50 years of age when they started cross-sex hormone treatment (with total androgen ablation). Epidemiological studies have shown that orchidectomy before the age of 40 prevents the development of prostate cancer and benign prostate hyperplasia, and the above cases do not contradict this notion. In most clinics, screening for the development of levels of prostate-specific antigen is not routinely done. The question could be raised whether a digital rectal examination of the prostate in combination with measuring prostate-specific antigen should be recommended in the follow-up of MTF transsexuals. A recent study in Germany indicated that the age-standardized incidence rate was $115 / 100000$ men per year, and the median age at diagnosis was 70 years (31). The three reported cases of prostate cancer in an unknown number of MTF set against this incidence do not lead to an evidence-based recommendation on routine testing. These cases of 
prostate cancer were all in subjects who started cross-sex hormones late in life. So, measurement of prostate-specific antigen may be limited to candidates with a late start of hormone treatment or those who have a family history of prostate cancer. Obviously, health economics are a factor in how comprehensive laboratory monitoring of a population will be.

\section{Ovarian cancer}

Ovariectomy is recommended in FTM when they are eligible for surgical sex reassignment, usually taking place 18-24 months after start of testosterone administration. Three cases of ovarian carcinoma in testosterone-treated FTM, diagnosed before they underwent surgery, have been reported $(32,33)$.

It has been described that the ovaries of FTM taking androgens resemble polycystic ovaries (34), but observations in the clinic of one of the authors (A M) are not confirmatory. The earlier notion that polycystic degenerated ovaries are more prone to develop cancer appears not tenable. But there is an upregulation of androgen receptors in ovarian and uterine tissue in long-termtreated FTM (35).

\section{Endometrial cancer}

To our knowledge, endometrial cancer has not been reported in FTM, but it remains a risk in FTM who have not been operated in the longer term. As indicated above, testosterone is partially aromatized to estradiol and the endometrium is exposed to unopposed action of estrogens. Unopposed estrogen action substantially increases the risk of endometrial carcinoma. The risks of unopposed estrogen action remain elevated long after actual use has been terminated.

In vitro studies have shown a direct effect of androgens on endometrial function by demonstrating the presence of androgen receptors in cultured endometrial epithelial cells (36).

The local availability of androgens and the finding that aromatase activity is present in both endometrial cancer and benign endometrial tissue support the hypothesis that aromatase activity in the endometrium may play a role in malignant transformation by converting androgens into mitogenic estrogens in the endometrial tissue (37). In women using continuous estrogen and testosterone regimes, a greater incidence of simple, low-grade endometrial hyperplasia was found than in women using continuous estrogen and progestin regimes (38). However, during short-term treatment with testosterone in postmenopausal women, there was no stimulation of endometrial proliferation. In addition, testosterone appeared to counteract endometrial proliferation induced by estrogen to a certain extent (39). It has been reported that testosterone is involved in the regulation of estrogen and progestin receptor expression in the endometrium which was decreased in glands after combined treatment with estradiol and testosterone (40). Testosterone administration to postmenopausal women resulting in physiological to slightly supraphysiological serum-free testosterone levels appeared to be safe for a period of at least 2 years (41).

Recently, it was shown that intermittent progesterone administration to women using continuous estrogen administration is, contrary to earlier beliefs, associated with an increased risk of endometrial cancer (42). Therefore, estrogen and continuous progestin are now recommended as menopausal hormone therapy in women who have not had a hysterectomy (43).

Testosterone administration to FTM usually leads to no or a small decline in plasma estradiol levels $(34,44)$. Since part of testosterone is aromatized to estradiol, plasma levels remain in such a range that biological effects can be expected $(34,44)$. Consequently, testosterone treatment in FTM generates biologically active levels of estradiol (proportional to the circulating levels of testosterone and sometimes higher than in postmeopausal women receiving estrogen treatment), which are not opposed by progesterone action. In FTM whose uterus has not surgically been removed, addition of a progestion might, therefore, be a consideration.

For surveillance, a once a year transvaginal, transrectal, or transabdominal ultrasound examination is recommended if there are no bleedings. Only when there is a bleeding during testosterone treatment do we perform additional examinations.

\section{Tumors of non-reproductive organs and sex steroids}

A number of tumors show sex differences in their prevalence and it is reasonable to assume that sex steroids might be one of the factors to explain this sex difference. This applies to tumors of the lung (adenocarcinoma, small cell carcinoma) (45), the colon (46), the bladder (but the latter mainly in animal models), and the brain, particularly meningiomas (47). These tumors have been observed in transsexuals but not in numbers that raise suspicion that cross-sex hormone treatment has been a significant factor in the development.

\section{Summary}

Malignancies related to cross-sex hormone treatment of transsexuals have so far, fortunately, been a rare occurrence. But, theoretically, there are valid reasons to expect a higher incidence in the future. Cross-sex hormone administration is relatively recent in medicine. Most transsexuals undergo treatment well before middle age and as part of that population start to age there is the implication of exposure to hormones over more than three or four decades. Furthermore, while usually crosshormone treatment is initiated in specialized centers, 
longer-term transsexuals are inclined to consult in more conveniently located general clinics, where physicians are less familiar with the condition and the awareness of potential complications such as malignancies might be lower.

\section{Acknowledgements}

The authors declare no conflict of interest. Funding was received from the Stichting Reproductieve Geneeskunde, Amsterdam, the Netherlands.

\section{References}

1 Gooren L. Hormone treatment of the adult transsexual patient. Hormone Research 200564 31-36.

2 Levy A, Crown A \& Reid R. Endocrine intervention for transsexuals. Clinical Endocrinology 200359 409-418.

3 Moore E, Wisniewski A \& Dobs A. Endocrine treatment of transsexual people: a review of treatment regimens, outcomes, and adverse effects. Journal of Clinical Endocrinology and Metabolism 200388 3467-3473.

4 Tangpricha V, Ducharme SH, Barber TW \& Chipkin SR. Endocrinologic treatment of gender identity disorders. Endocrine Practice $2003912-21$.

5 Anderson GL, Limacher M, Assaf AR, Bassford T, Beresford SA, Black H, Bonds D, Brunner R, Brzyski R, Caan B, Chlebowski R, Curb D, Gass M, Hays J, Heiss G, Hendrix S, Howard BV, Hsia J. Hubbell A, Jackson R, Johnson KC, Judd H, Kotchen JM, Kuller L, LaCroix AZ, Lane D, Langer RD, Lasser N, Lewis CE, Manson J, Margolis K, Ockene J, O'Sullivan MJ, Phillips L, Prentice RL, Ritenbaugh C, Robbins J, Rossouw JE, Sarto G, Stefanick ML, Van Horn L, Wactawski-Wende J, Wallace R \& Wassertheil-Smoller S. Effects of conjugated equine estrogen in postmenopausal women with hysterectomy: the Women's Health Initiative randomized controlled trial. Journal of American Medical Association 2004291 1701-1712.

6 Ito K. Hormone replacement therapy and cancers: the biological roles of estrogen and progestin in tumorigenesis are different between the endometrium and breast. Tohoku Journal of Experimental Medicine 2007212 1-12.

7 Ito K, Utsunomiya H, Suzuki T, Saitou S, Akahira J, Okamura K, Yaegashi N \& Sasano H. 17ß-hydroxysteroid dehydrogenases in human endometrium and its disorders. Molecular and Cellular Endocrinology 2006248 136-140.

8 van Kesteren PJ, Gooren LJ \& Megens JA. An epidemiological and demographic study of transsexuals in The Netherlands. Archives of Sexual Behaviour 199625 589-600.

9 van Kesteren PJ, Asscheman H, Megens JA \& Gooren LJ. Mortality and morbidity in transsexual subjects treated with cross-sex hormones. Clinical Endocrinology 199747 337-342.

10 Gooren LJ, Assies J, Asscheman H, de Slegte R \& van Kessel H. Estrogen-induced prolactinoma in a man. Journal of Clinical Endocrinology and Metabolism 198866 444-446.

11 Kovacs K, Stefaneanu L, Ezzat S \& Smyth HS. Prolactin-producing pituitary adenoma in a male-to-female transsexual patient with protracted estrogen administration. A morphologic study. Archives in Pathology and Laboratory Medicine 1994118 562-565.

12 Serri O, Noiseux D, Robert F \& Hardy J. Lactotroph hyperplasia in an estrogen treated male-to-female transsexual patient. Journal of Clinical Endocrinology and Metabolism 199681 3177-3179.

13 Pritchard TJ, Pankowsky DA, Crowe JP \& Abdul-Karim FW. Breast cancer in a male-to-female transsexual. A case report. Journal of American Medical Association 1988259 2278-2280.
14 Ganly I \& Taylor EW. Breast cancer in a trans-sexual man receiving hormone replacement therapy. British Journal of Surgery 199582341.

15 Woolcott CG, Sengupta SK, Hanna WM \& Aronson KJ. Estrogen and progesterone receptor levels in nonneoplastic breast epithelium of breast cancer cases versus benign breast biopsy controls. BMC Cancer $2008 \mathbf{8} 130$.

16 Henriksen KL, Sonne-Hansen K, Kirkegaard T, Frogne T \& Lykkesfeldt AE. Development of new predictive markers for endocrine therapy and resistance in breast cancer. Acta Oncologica 200847 795-801.

17 Gibson LJ, Dawson CK, Lawrence DH \& Bliss JM. Aromatase inhibitors for treatment of advanced breast cancer in postmenopausal women. Cochrane Database of Systematic Reviews, 2007 CD003370.

18 Lonning PE \& Geisler J. Indications and limitations of thirdgeneration aromatase inhibitors. Expert Opinions in Investigative Drugs 200817 723-739.

19 Tai YC, Domchek S, Parmigiani G \& Chen S. Breast cancer risk among male BRCA1 and BRCA2 mutation carriers. Journal of National Cancer Institute 200799 1811-1814.

20 Burcombe RJ, Makris A, Pittam M \& Finer N. Breast cancer after bilateral subcutaneous mastectomy in a female-to-male transsexual. Breast 200312 290-293.

21 Nicolas Diaz-Chico B, German Rodriguez F, Gonzalez A, Ramirez R, Bilbao C, Cabrera de Leon A, Aguirre Jaime A, Chirino R, Navarro D \& Diaz-Chico JC. Androgens and androgen receptors in breast cancer. Journal of Steroid Biochemistry and Molecular Biology $20071051-15$.

22 von Schoultz B. Androgens and the breast. Maturitas 200757 47-49.

23 Somboonporn W \& Davis SR. Testosterone effects on the breast: implications for testosterone therapy for women. Endocrine Reviews 200425 374-388.

24 Key TJ, Appleby PN, Reeves GK, Roddam A, Dorgan JF, Longcope C, Stanczyk FZ, Stephenson HE Jr, Falk RT, Miller R, Schatzkin A, Allen DS, Fentiman IS, Key TJ, Wang DY, Dowsett M, Thomas HV, Hankinson SE, Toniolo P, Akhmedkhanov A, Koenig K, Shore RE, Zeleniuch-Jacquotte A, Berrino F, Muti P, Micheli A, Krogh V, Sieri S, Pala V, Venturelli E, Secreto G, Barrett-Connor E, Laughlin GA, Kabuto M, Akiba S, Stevens RG, Neriishi K, Land CE, Cauley JA, Kuller LH, Cummings SR, Helzlsouer KJ, Alberg AJ, Bush TL, Comstock GW, Gordon GB, Miller SR \& Longcope C. Body mass index, serum sex hormones, and breast cancer risk in postmenopausal women. Journal of National Cancer Institute 200395 1218-1226.

25 The role of testosterone therapy in postmenopausal women: position statement of The North American Menopause Society. Menopause 200512 496-511; quiz 649.

26 van Kesteren P, Meinhardt W, van der Valk P, Geldof A, Megens J \& Gooren L. Effects of estrogens only on the prostates of aging men. Journal of Urology 1996156 1349-1353.

27 Goodwin WE \& Cummings RH. Squamous metaplasia of the verumontanum with obstruction due to hypertrophy: long-term effects of estrogen on the prostate in an aging male-to-female transsexual. Journal of Urology 1984131 553-554.

28 van Haarst EP, Newling DW, Gooren LJ, Asscheman H \& Prenger DM. Metastatic prostatic carcinoma in a male-to-female transsexual. British Journal of Urology $1998 \mathbf{8 1} 776$.

29 Dorff TB, Shazer RL, Nepomuceno EM \& Tucker SJ. Successful treatment of metastatic androgen-independent prostate carcinoma in a transsexual patient. Clinical Genitourinary Cancer 2007 5 344-346.

30 Thurston AV. Carcinoma of the prostate in a transsexual. British Journal of Urology 199473217.

31 Kraywinkel K, Lehnert M, Semjonow A \& Hense HW. Epidemiology of prostate cancer: Recent results from the Epidemiological Cancer Register of the District of Munster (Germany). Urologe A 200847 $853-859$. 
32 Hage JJ, Dekker JJ, Karim RB, Verheijen RH \& Bloemena E. Ovarian cancer in female-to-male transsexuals: report of two cases. Gynecologic Oncology 200076 413-415.

33 Dizon DS, Tejada-Berges T, Koelliker S, Steinhoff M \& Granai CO. Ovarian cancer associated with testosterone supplementation in a female-to-male transsexual patient. Gynecologic and Obstetric Investigation $2006 \mathbf{6 2} 226-228$.

34 Spinder T, Spijkstra JJ, van den Tweel JG, Burger CW, van Kessel H, Hompes PG \& Gooren LJ. The effects of long term testosterone administration on pulsatile luteinizing hormone secretion and on ovarian histology in eugonadal female to male transsexual subjects. Journal of Clinical Endocrinology and Metabolism 1989 69 151-157.

35 Chadha S, Pache TD, Huikeshoven JM, Brinkmann AO \& van der Kwast TH. Androgen receptor expression in human ovarian and uterine tissue of long-term androgen-treated transsexual women. Human Pathology 199425 1198-1204.

36 Tuckerman EM, Okon MA, Li T \& Laird SM. Do androgens have a direct effect on endometrial function? An in vitro study Fertility and Sterility $2000 \mathbf{7 4} 771-779$.

37 Jongen VH, Thijssen JH, Hollema H, Donker GH, Santema JG, Van der Zee AG \& Heineman MJ. Is aromatase cytochrome P450 involved in the pathogenesis of endometrioid endometrial cancer? International Journal of Gynecological Cancer 200515 529-536.

38 Filho AM, Barbosa IC, Maia H Jr, Genes CC \& Coutinho EM. Effects of subdermal implants of estradiol and testosterone on the endometrium of postmenopausal women. Gynecological Endocrinology 200723 511-517.

39 Zang H, Sahlin L, Masironi B, Eriksson E \& Linden Hirschberg A. Effects of testosterone treatment on endometrial proliferation in postmenopausal women. Journal of Clinical Endocrinology and Metabolism 200792 2169-2175.

40 Zang H, Sahlin L, Masironi B \& Hirschberg AL. Effects of testosterone and estrogen treatment on the distribution of sex hormone receptors in the endometrium of postmenopausal women. Menopause 200815 233-239.
41 Braunstein GD. Management of female sexual dysfunction in postmenopausal women by testosterone administration: safety issues and controversies. Journal of Sexual Medicine 20074 859-866.

42 Lacey JV Jr, Brinton LA, Lubin JH, Sherman ME, Schatzkin A \& Schairer C. Endometrial carcinoma risks among menopausal estrogen plus progestin and unopposed estrogen users in a cohort of postmenopausal women. Cancer Epidemiology, Biomarkers and Prevention 200514 1724-1731.

43 Doherty JA, Cushing-Haugen KL, Saltzman BS, Voigt LF, Hill DA, Beresford SA, Chen C \& Weiss NS. Long-term use of postmenopausal estrogen and progestin hormone therapies and the risk of endometrial cancer. American Journal of Obstetrics and Gynaecology 2007197139 e1-7.

44 Mueller A, Kiesewetter F, Binder H, Beckmann MW \& Dittrich R. Long-term administration of testosterone undecanoate every 3 months for testosterone supplementation in female-to-male transsexuals. Journal of Clinical Endocrinology and Metabolism 200792 3470-3475.

45 Dougherty SM, Mazhawidza W, Bohn AR, Robinson KA, Mattingly KA, Blankenship KA, Huff MO, McGregor WG \& Klinge CM. Gender difference in the activity but not expression of estrogen receptors alpha and beta in human lung adenocarcinoma cells. Endocrine-Related Cancer 200613 113-134.

46 Slattery ML, Sweeney C, Murtaugh M, Ma KN, Caan BJ, Potter JD \& Wolff R. Associations between vitamin D, vitamin D receptor gene and the androgen receptor gene with colon and rectal cancer. International Journal of Cancer $20061183140-3146$.

47 Wigertz A, Lonn S, Mathiesen T, Ahlbom A, Hall P \& Feychting M. Risk of brain tumors associated with exposure to exogenous female sex hormones. American Journal of Epidemiology $2006 \mathbf{1 6 4}$ 629-636.

Received 19 May 2008

Accepted 12 June 2008 